

American Journal of Biomedical Sciences

ISSN: 1937-9080

nwpii.com/ajbms

\title{
Controlled Release of Doxofylline from Biopolymer Based Hydrogels
}

\author{
Palapparambil Sunny Gils* a , Debajyoti Ray ${ }^{\text {b }}$, Prafulla Kumar Sahoo ${ }^{\text {a }}$ \\ a*Polymer Research Unit, Department of Chemistry, Utkal University, Vani Vihar, Bhubaneswar 751004, India \\ ${ }^{b}$ P.G. Department of Pharmaceutics, Sri Jayadev College of Pharmaceutical Sciences, Bhubaneswar 752101, India \\ *Corresponding author \\ Polymer Research Unit, \\ Department of Chemistry, \\ Utkal University, Vani Vihar, \\ Bhubaneswar, 751004, India. \\ Tel.: (91-674) 2582734 \\ Fax: (91-674) 2582734. \\ E mail: gils.ps@gmail.com
}

Received: 5 June 2010; $\mid$ Revised: 9 July 2010; $\mid$ Accepted: 22 July 2010

\begin{abstract}
In order to modify the xanthan gum (XG) polysaccharide and to develop the hydrogels meant for the drug delivery, we have prepared XG-g-poly [HEMA-co-AA] superporous hydrogel (SPH) through chemical cross-linking by graft copolymerization of 2-hydroxyethyl methacrylate (HEMA) and acrylic acid (AA) on to XG via redox initiator system of ammonium persulfate (APS) and $N, \quad N, \quad N^{\prime}, \quad N^{\prime}-$ tetramethylethylenediamine (TMED), in the presence of $N, N^{\prime}$-methylenebisacrylamide (MBA) crosslinking agent, sodium bicarbonate foaming agent, a triblock copolymer of polyoxyethylene/ polyoxypropylene/ polyoxyethylene as a foam stabilizer. Characterization of SPH was done by FT-IR, TGA, SEM, HPLC and GCMS. The prepared SPH were successfully loaded with Doxofylline (DF) drug and formulation $\mathrm{H}_{10}$ showed higher \% drug content (98 \pm 2.3$)$ and \% drug entrapment efficiency (83 \pm 2.0$)$. From the in Vitro drug release study in $\mathrm{pH}$ progressive media, formulation $\mathrm{H}_{10}$ showed comparatively higher release extending upto 24h.The mechanism of DF release from the SPH matrix was found to be of diffusion type.
\end{abstract}

Keywords: Hydrogel, Polysaccharide, Monomer residuals, Doxofylline, Controlled drug delivery.

\section{Introduction}

The successful optimization and development of drug entity, design of dosage form then plays important role. Hence, research continuously keeps on searching for ways to deliver drugs over an extended period of time. The use of hydrogel systems for controlling the release of drugs has increasingly well known respond to surrounding conditions such as $\mathrm{pH}$, ionic strength, temperature and frequent changes of environment in the GItract, which has a variation of $\mathrm{pH}$ from the stomach to intestine [1]. Hydrogels from natural polymers, especially polysaccharides have been widely used of their advantageous properties over 
synthetic polymers such as non-toxicity, biocompatibility, biodegradability ability to modify the properties of aqueous environment, capacity to thicken, emulsify, stabilize, encapsulate, swell and to form gels, films [2-4]. Although natural gums and their derivatives are used widely in pharmaceutical dosage forms, their use as biodegradable polymeric materials to deliver bioactive agents has been hampered by the synthetic materials. These natural polysaccharides do hold advantages over the synthetic polymers, generally because they are nontoxic, less expensive, and freely available. Natural gums can also be modified to have tailor-made materials for drug delivery systems and thus can compete with the synthetic biodegradable excipients available in the market.

Xanthan gum (XG) is an extracellular polysaccharide secreted by the microorganism Xanthomonas campestris. It is a complex polysaccharide consisting of a primary chain of $\beta$ D-(1, 4)-glucose backbone, which has a branching trisaccharide side chain comprised of $\beta$-D- $(1,2)$ mannose, attached to $\beta$-D- $(1,4)$-glucuronic acid, which terminates in a final $\beta$-d-mannose. Because of its inertness, biocompatibility, drug releaseretarding property, $\mathrm{XG}$ is widely used in combination with other monomers and polymers to develop hydrogel formulations with controlled release characteristics [5].

Doxofylline (DF) is a novel xanthine bronchodilator indicated for the treatment of bronchial asthma and chronic obstructive pulmonary disease (COPD) in adults [6]. According to the American Thoracic Society, asthma is a disease characterized by an increased responsiveness of the trachea and bronchi to various stimuli and manifested by excessive narrowing of the airways and which changes in severity either spontaneously or as a result of therapy. The various therapeutic approaches available and being used to treat asthma aimed at treating symptoms rather than curative. So, patients have to live with their problem throughout their life and, if not managed properly, it can significantly affect their quality of life as well as their productive contributions to society. Chemically DF is 7-(1, 3-dioxalan-2ylmethyl)theophylline. It competitively inhibits phosphodiesterase, the enzyme that degrades cyclic 3', 5'-adenosinemono phosphate (cAMP). It appears to have decreased affinities toward adenosine $\mathrm{A} 1$ and $\mathrm{A}_{2}$ receptors, which may account for the better safety profile of the drug. The bronchodialating activities of DF have been demonstrated in clinical trials involving patients with either bronchial asthma or chronic obstructive pulmonary disease. In contrast to other bronchodilators, experimental and clinical studies have shown that the drug is devoid of direct stimulatory effects. This may be of importance because the arrhythmogenic actions of bronchodilators may have a negative impact on the survival of patients with respiratory diseases. The aim of this work was not only to characterize new type of SPH, XG-g-poly [HEMA-co-AA], but also to evaluate the usefulness of these polysaccharide-based SPH for delivering the antiasthmatic dug DF in a controlled manner. Controlling the release of the drug DF might be helpful in reducing toxicity, side effects and dose frequency of DF.

\section{Experimental}

\subsection{Materials}

Xanthan gum (XG) was purchased from Sigma, USA. Ammonium persulfate (APS), $N, N$, $N$ 'N'-tetramethylethylenediamine (TMED), $N$, $N$ 'methylenebisacrylamide (MBA) and Sodium bicarbonate $\left(\mathrm{NaHCO}_{3}\right)$ were purchased from Fluka (Buchs, Switzerland). Lutrol $\mathrm{F}^{\circledR} 127$ was obtained from BASF (Ludwigshafen, Germany). Acrylic acid and 2-hydroxyethyl methacrylate (Merck, Darmstadt, Germany) were vacuum distilled at $63{ }^{\circ} \mathrm{C} / 12 \mathrm{~mm} \mathrm{Hg}$ and $50{ }^{\circ} \mathrm{C} / 50 \mathrm{~mm}$ $\mathrm{Hg}$ respectively, prior to use in order to remove the inhibitor. In HEMA vacuum distillation, hydroquinone was added to prevent polymerization. All other chemicals were also of analytical grade. Milli-Q grade deionized water was used for preparing the solutions.

\subsection{Synthesis of homopolymers, pHEMA, pAA and copolymer poly [HEMA-co- AA]}

The above homopolymers and copolymers were synthesized as per the earlier reports [7] with 
little modification as described below without adding $\mathrm{XG}$.

\subsection{Synthesis of graft copolymer, XG-g-poly [HEMA-co-AA]}

A pre-weighed amount of XG (1.0g) was added to $30 \mathrm{ml}$ deionized water in a $500 \mathrm{ml}$ reactor equipped with a mechanical stirrer (RZR 2021, a three-blade propeller type, Heidolph, Schwabach, Germany) and stirred (250 rpm) for $10 \mathrm{~min}$. The reactor was placed in a thermostated water bath to control the reaction temperature at $80{ }^{\circ} \mathrm{C}$. After dissolving $\mathrm{XG}$ and homogenizing the mixture, the monomers HEMA, AA and the crosslinker, MBA, Lutrol $\mathrm{F}^{\circledR} 127$ (foam stabilizer) were simultaneously added and the reaction mixture was stirred for $15 \mathrm{~min}$. Then the initiator APS (oxidant) and TMED (reductant), $\mathrm{NaHCO}_{3}$ (foaming agent) were added (Table 1). The solution was stirred at 400-500 rpm while maintaining the temperature and inert atmosphere. The temperature was maintained at $80{ }^{\circ} \mathrm{C}$ and the reaction mixture was stirred continuously for $4 \mathrm{~h}$. The low molecular weight substances remaining in the samples after polymerization were extracted with boiling ethanol for $24 \mathrm{~h}$. The product was collected by centrifugation and dried in the oven under vacuum at $60{ }^{\circ} \mathrm{C}$ for $24 \mathrm{~h}$. The dried graft polymer was added to $300 \mathrm{ml}$ deionized water. It was allowed to swell during agitation in a water bath at the constant temperature of $60^{\circ} \mathrm{C}$ for $24 \mathrm{~h}$. Then it was extracted with ethanol in a soxhlet for $6 \mathrm{~h}$ followed by water at $100{ }^{\circ} \mathrm{C}$ for $72 \mathrm{~h}$. The precipitate was filtered and dried under vacuum at $60{ }^{\circ} \mathrm{C}$.

Table 1 Composition of the feed mixture Reaction conditions: Xanthan gum: 1g, Lutrol $\mathrm{F}^{\circledR} 127: 100 \mathrm{mg}$, $\mathrm{NaHCO}_{3}: 0.5 \mathrm{~g}, \mathrm{H}_{2} \mathrm{O}: 30 \mathrm{ml}$, Temperature: $80{ }^{\circ} \mathrm{C}$

\begin{tabular}{lllllll}
\hline $\begin{array}{l}\text { Polymer } \\
\text { code }\end{array}$ & MBA $(\mathrm{g})$ & APS $(\mathrm{g})$ & TMED $(\mathrm{ml})$ & HEMA $(\mathrm{ml})$ & AA $(\mathrm{ml})$ & \% Yield \\
\hline $\mathrm{H}_{1}$ & 0.1 & 0.1 & 0.1 & 2.5 & 2.5 & 49 \\
$\mathrm{H}_{2}$ & 0.2 & 0.1 & 0.1 & 2.5 & 2.5 & 51 \\
$\mathrm{H}_{3}$ & 0.3 & 0.1 & 0.1 & 2.5 & 2.5 & 46 \\
$\mathrm{H}_{4}$ & 0.1 & 0.2 & 0.1 & 2.5 & 2.5 & 47 \\
$\mathrm{H}_{5}$ & 0.1 & 0.3 & 0.1 & 2.5 & 2.5 & 53 \\
$\mathrm{H}_{6}$ & 0.1 & 0.2 & 0.2 & 2.5 & 2.5 & 73 \\
$\mathrm{H}_{7}$ & 0.1 & 0.2 & 0.3 & 2.5 & 2.5 & 49 \\
$\mathrm{H}_{8}$ & 0.1 & 0.2 & 0.2 & 5.0 & 2.5 & 58 \\
$\mathrm{H}_{9}$ & 0.1 & 0.2 & 0.2 & 7.5 & 2.5 & 57 \\
$\mathbf{H}_{\mathbf{1 0}}$ & $\mathbf{0 . 1}$ & $\mathbf{0 . 2}$ & $\mathbf{0 . 2}$ & $\mathbf{2 . 5}$ & $\mathbf{5 . 0}$ & $\mathbf{7 7}$ \\
$\mathrm{H}_{11}$ & 0.1 & 0.2 & 0.2 & 2.5 & 7.5 & 71 \\
\hline
\end{tabular}

\subsection{Characterization}

FTIR spectra of individual and crosslinked polymers were recorded in the range 400-4000 $\mathrm{cm}^{-1}$ on a Perkin Elmer Paragon 500 FTIR spectrophotometer using $\mathrm{KBr}$ pellets. The thermogravimetric analysis data were recorded with a shimadzu DTG-50 thermal analyzer. The samples were heated from room temperature to $600{ }^{\circ} \mathrm{C}$ at a heating rate of $10^{\circ} \mathrm{C}$ per min. The SEM of goldcoated samples were obtained using JSM 6390LV scanning electron microscope (Jeol Ltd,
Japan) at a magnification of $\mathrm{x} 5$ to 300,000 (Resolution-HV $3.0 \mathrm{~nm}$ ). Residual AA was detected and quantified by HPLC (Prominence, Shimadzu Corporation, Japan). The chromatographic system consisted of a computercontrolled pump (model LC 20AT), autosampler (model SIL-10AF) equipped with a $200 \mu 1$ sample loop, photodiode array (PDA) detector (model SPD-M20A). Shimadzu LC Solution software was used for the system and data management. The separation was performed in isocratic mode at a 
flow rate of $1.5 \mathrm{ml} / \mathrm{min}$ and a temperature of $40{ }^{\circ} \mathrm{C}$ on an analytical column Luna $5 \mu \mathrm{C} 18,250$ x 4.6 $\mathrm{mm}$ (Phenomenex, USA). The mobile phase was aqueous $0.01 \%$ orthophosphoric acid [8] and the injection volume was $25 \mu \mathrm{l}$. Residual HEMA analysis was performed by using GCMS (Agilent $6890 \mathrm{~N}$ GC coupled with 5975 inert MSD). The GC was equipped with an autosampler (Agilent 7683 B). For chromatographic separation, a capillary column with following specifications was used: HP-5MS with length $30 \mathrm{~m}$, id. of 0.25 $\mathrm{mm}$ and a film thickness of $0.25 \mu \mathrm{m}$ (J\&W Scientific). The carrier gas was helium with a constant flow of $0.7 \mathrm{ml} / \mathrm{min}$. Injection was splitless and purge flow of helium gas was 50 $\mathrm{ml} / \mathrm{min}$. Injector temperature was $250{ }^{\circ} \mathrm{C}$. The temperature program for the oven was as follows: start point at $50{ }^{\circ} \mathrm{C}$, with a rate of $15^{\circ} \mathrm{C} / \mathrm{min}$ up to $160^{\circ} \mathrm{C}$, from 160 to $200^{\circ} \mathrm{C}$ with rate of $10^{\circ} \mathrm{C} / \mathrm{min}$, hold time at $200{ }^{\circ} \mathrm{C}$ for $1 \mathrm{~min}$ and from 200 to 300 ${ }^{\circ} \mathrm{C}$ with rate of $10^{\circ} \mathrm{C} / \mathrm{min}$, hold time at $300{ }^{\circ} \mathrm{C}$ for $2 \mathrm{~min}$. Source and quadrupole temperatures of MSD (mass selective detector) were 230 and 150 ${ }^{\circ} \mathrm{C}$ respectively. The transfer line temperature was $280^{\circ} \mathrm{C}$.

\subsection{Drug loading}

XG-g-poly [HEMA-co-AA] SPH was loaded with DF (as model drug) by soaking in an aqueous solution containing $10 \%$ (w/v) of DF. Soaking was done for nearly 2 days in order to achieve complete equilibrium. The formulations were filtered and the surface-adhered drug solution was removed by washing and blotting with soft filter paper and dried in air before storing in a desiccator.

\subsection{Drug entrapment efficiency (\%)}

DF loaded XG-g-poly [HEMA-co-AA] SPH $(50 \mathrm{mg})$ from each batch were dispersed separately in water and kept for $24 \mathrm{~h}$, filtered through $0.22 \mu \mathrm{m}$ microfilter and absorbance was measured using UV/VIS spectrophotmeter (Varian, Cary 50 Bio,USA) at $274 \mathrm{~nm}$. The obtained absorbance was plotted on the standard curve to get the exact concentration of the entrapped drug. Calculating this concentration with dilution factor we get the percentage of actual drug encapsulated in hydrogel. DF content were determined and expressed in terms of weight of DF per weight of SPH, thus determining the actual entrapment ratio (AER).

$\%$ of Entrapment efficiency $=$ AER/TER x 100 [1] where AER $=$ Measured drug wt $/$ formulation wt and

TER = Drug wt. /drug wt. and polymer wt.

\subsection{Swelling behavior of SPH}

Swelling behavior of the prepared SPH was performed by tea bag [9] method. About $0.100 \mathrm{~g}$ of sample was added to a small bag made of nylon (50 mm x $90 \mathrm{~mm} ; 200 \mathrm{mesh}$ ). Then the bag was completely immersed in the swelling medium $(200 \mathrm{ml})$ at room temperature for $24 \mathrm{~h}$ to reach the swelling equilibrium. The $\mathrm{pH}$-dependent equilibrium swelling of the SPH were studied both in the simulated gastric fluid (SGF, $3.2 \mathrm{mg} / \mathrm{ml}$ pepsin in $0.05 \mathrm{M}$ hydrochloric acid, $\mathrm{pH} 1.2$ ) and simulated intestinal fluid (SIF, $10 \mathrm{mg} / \mathrm{ml}$ pancreatin in Sorensen's phosphate buffer, $\mathrm{pH}$ 7.4). Adhered liquid droplets on the surface of the particles were removed by blotting with tissue papers. The swollen SPH were weighed and dried in an oven at $60{ }^{\circ} \mathrm{C}$ for $6 \mathrm{~h}$ until there was no change in the dry mass of the samples.

The equilibrium swelling (ES) was defined as follows:

$\left.\mathrm{ES}(\mathrm{g} / \mathrm{g})=\underline{\left(\mathrm{W}_{\mathrm{S}}\right.} \underline{\mathrm{W}}_{\mathrm{d}} \frac{\mathrm{W}}{\mathrm{d}}\right)$

Where $\mathrm{W}_{\mathrm{S}}$ and $\mathrm{W}_{\mathrm{d}}$ are the weights of the swollen sample and the weight of dried gel, respectively.

\subsection{In vitro drug release study in $\mathrm{pH}$ progressive media}

The in vitro drug release was carried out by filling the calculated amount of DF loaded SPH in capsule shell (size 2), analyzed using USP-I basket dissolution apparatus and proper simulation of gastro intestinal (GIT) condition was maintained by altering the $\mathrm{pH}$ of dissolution medium at different time intervals following two stepdissolution conditions. To simulate the physiological conditions of GIT, first $2 \mathrm{~h}$ of dissolution were carried out in $900 \mathrm{ml}$ of simulated gastric fluid (SGF, $3.2 \mathrm{mg} / \mathrm{ml}$ pepsin in $0.05 \mathrm{M}$ hydrochloric acid, $\mathrm{pH} 1.2$ ) and the rest of 
the time in $900 \mathrm{ml}$ of simulated intestinal fluid (SIF, $10 \mathrm{mg} / \mathrm{ml}$ pancreatin in Sorensen's phosphate buffer, $\mathrm{pH}$ 7.4). The media was stirred at $100 \mathrm{rpm}$ at $37 \pm 0.5^{\circ} \mathrm{C}$. At predetermined time intervals, specified amount of dissolution medium was removed; filtered through $0.22 \mu \mathrm{m}$ microfilter and analyzed in UV spectrophotometer at $274 \mathrm{~nm}$. After each sampling an equal volume of fresh dissolution media was added to the dissolution medium. All the dissolution studies were repeated six times.

\section{2 .9. Kinetics of drug release}

Different mathematical models may be applied for describing the kinetics of the drug release process from the hydrogel matrix; the most suited being the one which best fits the experimental results. The kinetics of DF release from SPH was determined by finding the best fit of the dissolution data (drug release vs. time) to distinct models: Zero order[eq.1], first-order [eq.2] and Higuchi [eq. 3] .

$$
\begin{aligned}
& \mathrm{Q}_{\mathrm{t}}=\mathrm{k}_{0} \mathrm{t} \\
& \mathrm{Q}_{\mathrm{t}}=\mathrm{Q}_{\infty}\left(1-\mathrm{e}^{-\mathrm{k}{ }_{1} \mathrm{t}}\right) \\
& \mathrm{Q}_{\mathrm{t}}=\mathrm{k}_{\mathrm{H}} \mathrm{t}^{1 / 2}
\end{aligned}
$$

where $\mathrm{Q}_{\infty}$ being the total amount of drug in the matrix, $\mathrm{k}_{0}$ the zero order kinetic constant, $\mathrm{k}_{1}$ the first order kinetic constant and $\mathrm{k}_{\mathrm{H}}$ representing the Higuchi rate constant.

\subsection{Stability studies}

The physical stability of the DF loaded SPH of different batches was evaluated after storing for three months under different temperature and humidity conditions. Particular amount of dried SPH from each batch were packed in amber glass vials and stored in the stability chamber at $40{ }^{\circ} \mathrm{C}$ $175 \%$ relative humidity condition as per I.C.H. guidelines [10]. Samples of definite amount from each batch were withdrawn after three months to see the effect of DF release from the SPH on storage.

\section{Results and Discussion}

In the present study, we have attempted to graft HEMA and AA on the XG backbones. The reactive vicinal group where the grafting is initiated on $\mathrm{XG}$ backbone is $\mathrm{CH}_{2} \mathrm{OH}$. APS and TMED were used as the redox initiating system. The reaction between APS and TMED produces the trimethyl ethylene methylene diamine radical and hydrogen sulfate free radical. The anionradicals abstract hydrogen from the $\mathrm{XG}$ backbones to form corresponding macroradicals. These macroradicals initiate grafting of HEMA and AA onto XG backbones leading to a graft copolymer. In addition, in the presence of a crosslinker, i.e., MBA, crosslinking reaction occurred and finally a three dimensional network was obtained. The prepared SPH were loaded with model drug DF and different drug delivery aspects were compared to find out the controlled release capacity of the SPH.

\subsection{Fourier transform infrared spectra}

The FT-IR spectra of the SPH along with XG, pHEMA, pAA, poly [HEMA-co-AA], XG-g-poly [HEMA-co-AA] are shown in Fig.1A. In case of pure XG (a), a broad absorption peak at $3450 \mathrm{~cm}^{-1}$ indicating the hydrogen bonded $\mathrm{OH}$ groups. Two peaks, one at $1615 \mathrm{~cm}^{-1}$ and the other at $1476 \mathrm{~cm}^{-1}$, are attributed to $\mathrm{COO}^{-}$groups. Additional characteristic absorption bands of $\mathrm{XG}$ appear at $1417 \mathrm{~cm}^{-1}$ and $1023 \mathrm{~cm}^{-1}$ due to $\mathrm{C}-\mathrm{H}$ bending and $\mathrm{O}-\mathrm{H}$ bending vibrations, respectively. The peaks at $1568 \mathrm{~cm}^{-1}(\mathrm{C}=\mathrm{O}$ asymmetric stretching $)$ and $1406 \mathrm{~cm}^{-1}(\mathrm{C}=\mathrm{O}$ symmetric stretching) are due to the carboxylate anion (Dos Santos et al., 2006) of pAA (c). The sharp peak at $1724 \mathrm{~cm}^{-1}$ corresponds to the ester group present in pHEMA (b). For poly [HEMA-co-AA] and XG-g-poly [HEMA-co-AA] $(d, e)$, the characteristic peaks for both HEMA and AA are present with little shifting of the position. The peaks at 1162 and $1080 \mathrm{~cm}^{-1}$ corresponding to C-O-C stretching also confirms the presence of ester group. Moreover, the O-H stretching peak at $3426 \mathrm{~cm}^{-1}$ of the grafted copolymer had a greater intensity when adding XG. The characteristic IR absorption peaks of DF Fig.1B (a) at $1717 \mathrm{~cm}^{-1}$ (C=O stretch), $1565 \mathrm{~cm}^{-1}$ (C=C stretch), $1484 \mathrm{~cm}^{-1}$ $(\mathrm{C}=\mathrm{N}$ stretch $), 1445 \mathrm{~cm}^{-1}(\mathrm{C}-\mathrm{H}$ bend $)$ and $1187 \mathrm{~cm}^{-}$ ${ }^{1}$ (C-N vibration) were also present in the $\mathrm{SPH}$ formulation $\mathrm{H}_{10}$ (b) with no shifting in the major peaks, indicate that no interaction occurred between the DF and SPH. 


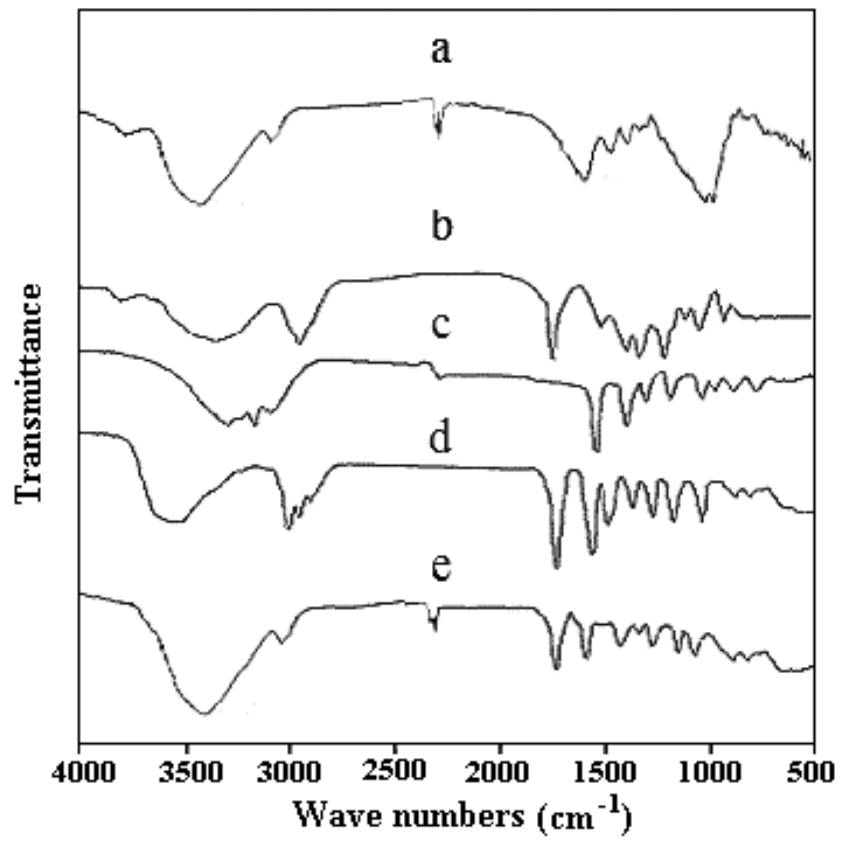

Figure 1A FTIR spectra of (a) XG (b) pHEMA (c) pAA (d) poly [HEMA-co-AA] (e) XG-g-poly [HEMA-coAA]

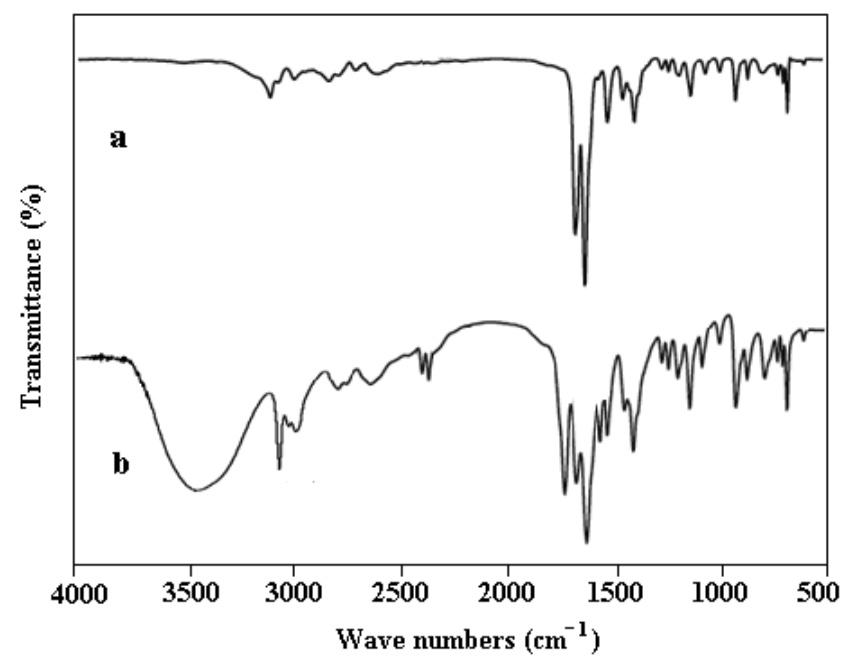

Figure 1B (a) Pure Doxofylline (b) Doxofylline loaded SPH formulation $\mathrm{H}_{10}$

\subsection{Thermogravimetric analysis}

The thermal behaviors of XG, pAA, pHEMA, poly [HEMA-co-AA], XG-g-poly [HEMA-coAA] were studied at room temperature $\left(28 \pm 2{ }^{\circ} \mathrm{C}\right)$ by comparing their thermogram curves as shown in Fig.2. For XG (a) the first weight loss step occured over the range $30-91.0{ }^{\circ} \mathrm{C}$ might be attributed to the loss of residual water and major weight loss occurred over the range 251.0-331.0 ${ }^{\circ} \mathrm{C}$. The thermogram of pAA (b) showed three decomposition stages. The first decomposition stage in the range $49.8-101{ }^{\circ} \mathrm{C}$ was attributed to the loss of bound water. The second one in the interval of $215.1-303.2{ }^{\circ} \mathrm{C}$ had been described to the dehydration and decarboxylation of the polymer which leads to the formation of inter- and intra-molecular anhydride. The third decomposition stage in the range $365.2-470.1{ }^{\circ} \mathrm{C}$ was a result of the degradation of the residual polymer. For pHEMA (e) the decomposition range was found to be in between 337.0 to $480.2{ }^{\circ} \mathrm{C}$. For poly [HEMA-co-AA] (d) degradation temperature in between $50-178{ }^{\circ} \mathrm{C}$ and $265.1-369.4{ }^{\circ} \mathrm{C}$ were because of loss of $\mathrm{H}_{2} \mathrm{O}$ and $\mathrm{CO}_{2}$ molecule respectively. The thermal stability of the grafted $\mathrm{XG}$ (c) is improved as is obvious from the TGA curve. In the TGA curve of XG about $50.1 \%$ weight loss takes place in the temperature range of 251.0-381.2 ${ }^{\circ} \mathrm{C}$, while it was $36.3 \%$ in grafted copolymer. Moreover, the high char yield, up to $27.8 \mathrm{wt} \%$, at $600{ }^{\circ} \mathrm{C}$ observed in thermogram indicates that the graft copolymers have significantly higher thermal stability than that of the XG (Char yield $=26.9 \%)$, which was caused by the strong bonding between the grafting polymer chains and $\mathrm{XG}$ matrices in the graft copolymer. These studies indicated the grafting of poly [HEMA-co-AA] onto $\mathrm{XG}$ to an overall improvement in the thermal stability.

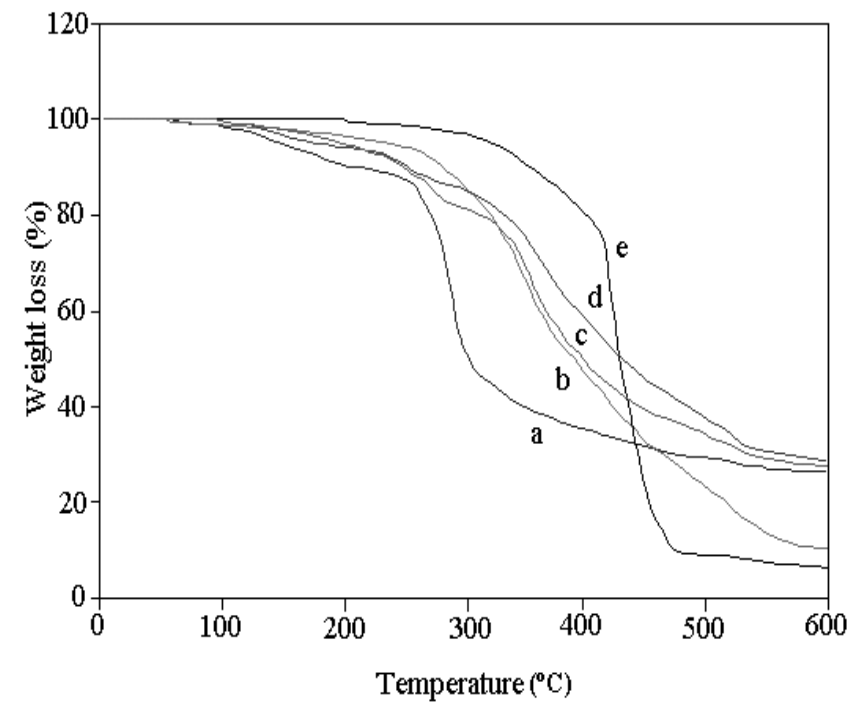

Figure 2 TGA of (a) XG (b) pAA (c) XG-g-poly [HEMA-co-AA], (d) poly [HEMA-co-AA], (e) pHEMA

(C) 2010 by NWPII. All rights reserved. 


\subsection{Scanning Electron Microscopy}

Fig. 3 showed the cross-sectional view of the SEM image of dry SPH $\left(\mathrm{H}_{10}\right)$. From the SEM image, one could identify the pores in the SPH networks and the connectivity of the pores. The evaporation of water on drying made the macroporous structure clearly prominent, as evidenced from the SEM photograph.

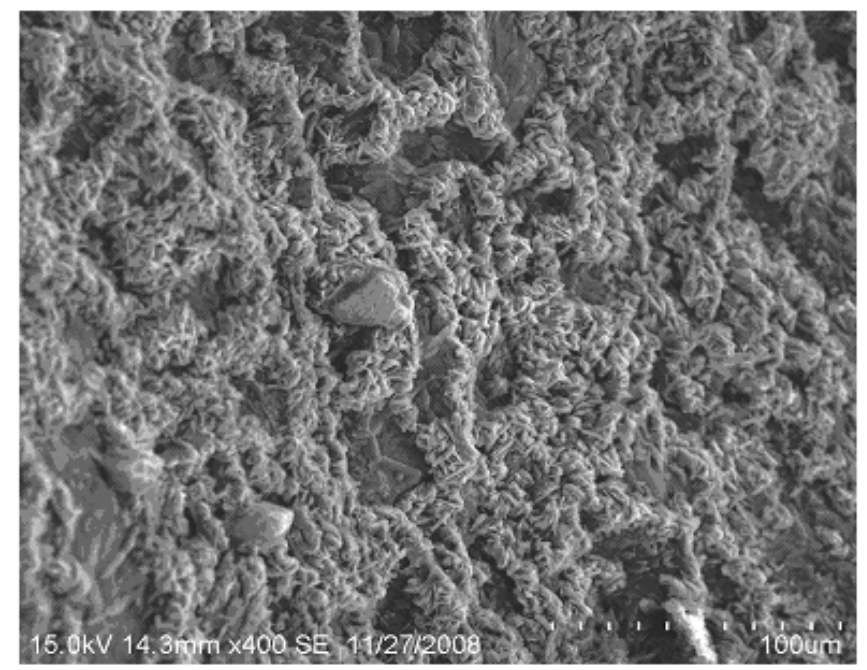

Figure 3 SEM image of the SPH with (HEMA/AA) $(\mathrm{v} / \mathrm{v})$ ratio $1: 2$

\subsection{Residual AA determination}

Dried SPH $(0.100 \mathrm{~g})$ was accurately weighed and added to $25 \mathrm{ml} 0.01 \%$ orthophosphoric acid solution $(\mathrm{pH}=2.3)$ in a polypropylene tube. After vortex (Cyclo mixer, CM 101, Remi Instruments, India) for $10 \mathrm{~min}$ the sample hydrogels were placed in an orbital shaker (Labline instruments, India) at $37^{\circ} \mathrm{C}$ with constant agitation (200 rpm) for $24 \mathrm{~h}$. Then it was centrifuged (model 510R, Eppendorf, Germany) for $10 \mathrm{~min}$ at $3500 \mathrm{rpm}$ at 4 ${ }^{\circ} \mathrm{C}$. The supernatant was taken by means of a syringe, then filtered through a $0.45 \mu \mathrm{m}$ syringe filter [Millipore millex-HV, Hydrophilic PVDF (polyvinylidene fluoride)] and finally put in a sample vial (Waters, USA). The PDA absorbance over the 190-400 $\mathrm{nm}$ range was recorded. The wavelength used for quantification was $196 \mathrm{~nm}$. A standard calibration curve between the concentration of acrylic acid and the area of the chromatographic peak was plotted in the range $0.01-0.5 \mu \mathrm{g} / \mathrm{ml}$. The regression equation was $\mathrm{Y}=\mathrm{a}$ $\mathrm{X}+\mathrm{b}$, where $\mathrm{Y}$ denotes peak area and $\mathrm{X}$ is the concentration of AA $(\mu \mathrm{g} / \mathrm{ml}) . \mathrm{a}=1.1101 \times 10^{-4}$ and $b=0.0$. The correlation coefficient was 0.9999. During the extraction the total residual monomer in form of either acid or its salt, diffuses from the gel network to acid solution, as it was allowed to swell in excess of orthophosphoric acid solution. It can be seen from the Fig.4 that the amount of the residual AA was decreased markedly after soxhlet extraction (the amount was decreased from $13.9 \mu \mathrm{g} / \mathrm{g}$ to $0.19 \mu \mathrm{g} / \mathrm{g}$ ). The decrease in residual AA content was due to its diffusion from gel network to the water, as it was allowed to swell in the excess of water, but a little amount was still detected as few monomers were trapped in the polymer chain.

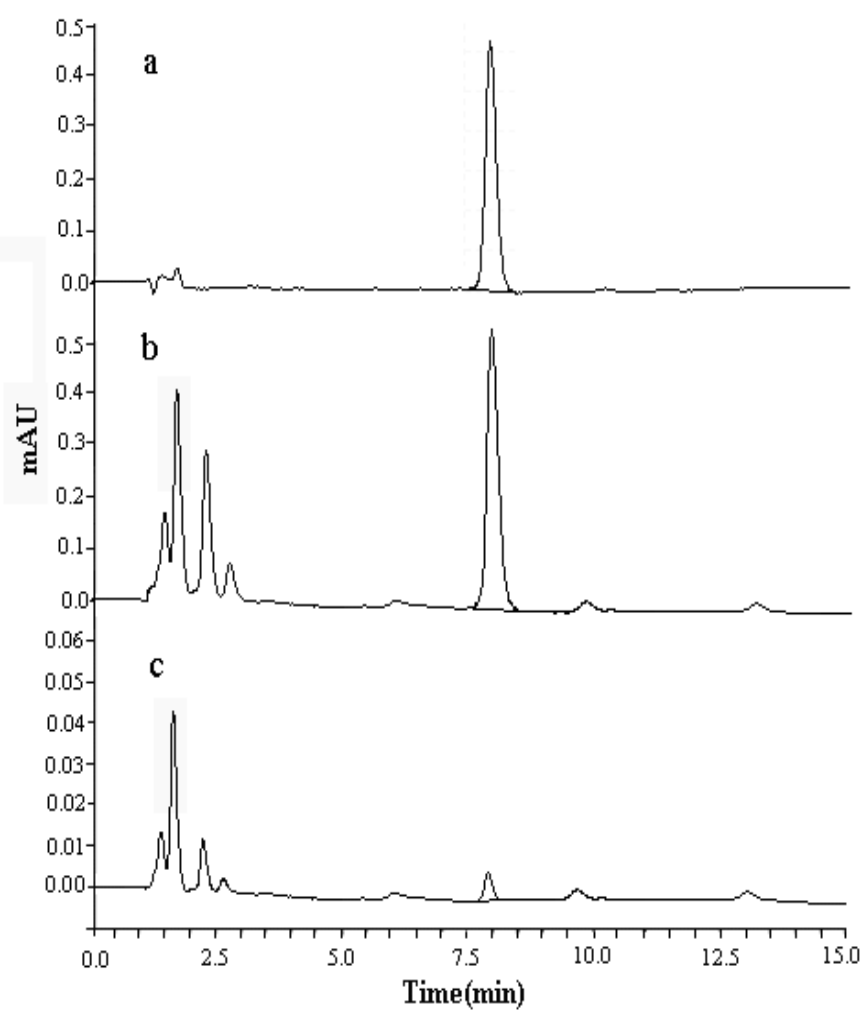

Figure 4 HPLC chromatogram of residual AA in SPH $\left(\mathrm{H}_{10}\right)$ (a) AA standard $0.05 \mu \mathrm{g} / \mathrm{ml}$. (b) Before soxhlet extraction, (c) After soxhlet extraction.

\subsection{Residual HEMA determination}

Dried SPH $(0.100 \mathrm{~g})$ was accurately weighed and added to $5 \mathrm{ml}$ ethanol [10] in an amber vial (Supleco, USA). After vortex for $10 \mathrm{~min}$ the sample beads were placed in an orbital shaker at $37{ }^{\circ} \mathrm{C}$ for $24 \mathrm{~h}$ with constant agitation $(200 \mathrm{rpm})$. 
Then it was centrifuged for $10 \mathrm{~min}$ at $3500 \mathrm{rpm}$ at $4{ }^{\circ} \mathrm{C}$. The supernatant was collected and added to $5 \mathrm{ml}$ acetone and vortex. The solutions were evaporated (Turb Vap LV,Caliper Life science,USA) to approximately $50 \mu \mathrm{l}$ at $45^{\circ} \mathrm{C}$, made up to $1 \mathrm{ml}$ using acetone, filtered and $1 \mu \mathrm{l}$ was injected into GCMS. The identification and quantification of the analytes were performed by using the mass spectrometer in full scan mode, scanning from 0 to $150 \mathrm{~m} / \mathrm{z}$ (molecular ion, $\mathrm{m} / \mathrm{z}=$ 130.0; characteristic ions, $\mathrm{m} / \mathrm{z}=69$ and 87). The identification of the different compounds was then based on comparison of the obtained full scan spectra with spectra in the NIST library (National Institute of Science and Technology, Gaithersburg, MD, USA) (Fig.5 a and b). The quantifications were performed by constructing mass fragmentograms of abundant ions characteristic for standard HEMA and comparing the area under the peak of HEMA $(1 \mu \mathrm{g} / \mathrm{ml})$ with the area of sample (Fig.5 $\mathrm{c}$ and d). The amount of residual HEMA was found to be $0.74 \mu \mathrm{g} / \mathrm{g}$.

\subsection{Swelling behavior}

Swelling studies of the prepared SPH $\left(\mathrm{H}_{6}, \mathrm{H}_{10}\right.$, and $\mathrm{H}_{11}$ ) were performed in simulated gastric fluid (SGF) and simulated intestinal fluid (SIF) as shown in Fig.6. From the study, swelling of SPH in SIF media was found to be much higher than that in SGF. Under acidic pH values (SGF), most of the carboxylate anions are protonated, so the main anion-anion repulsive forces are eliminated and consequently swelling values are decreased. At higher $\mathrm{pH}$ values (SIF), some of the carboxylate groups are ionized and the electrostatic repulsion between $\mathrm{COO}^{-}$groups causes an enhancement of the swelling capacity. The highest swelling capacity was obtained at 1:2 $(\mathrm{v} / \mathrm{v})$ ratio of HEMA: AA $\left(\mathrm{H}_{10}\right)$ in both the media.

\subsection{Drug entrapment efficiency (\%)}

Entrapment efficiency is the amount of added drug (in percent) that is encapsulated in the formulation (Table 2). Entrapment efficiency was calculated as the ratio of the weight of DF content in the formulation and the DF introduced in the process. Low coefficient of variance $(<2 \%)$ in $\%$ DF entrapment indicates uniformity of drug entrapment in different batches.
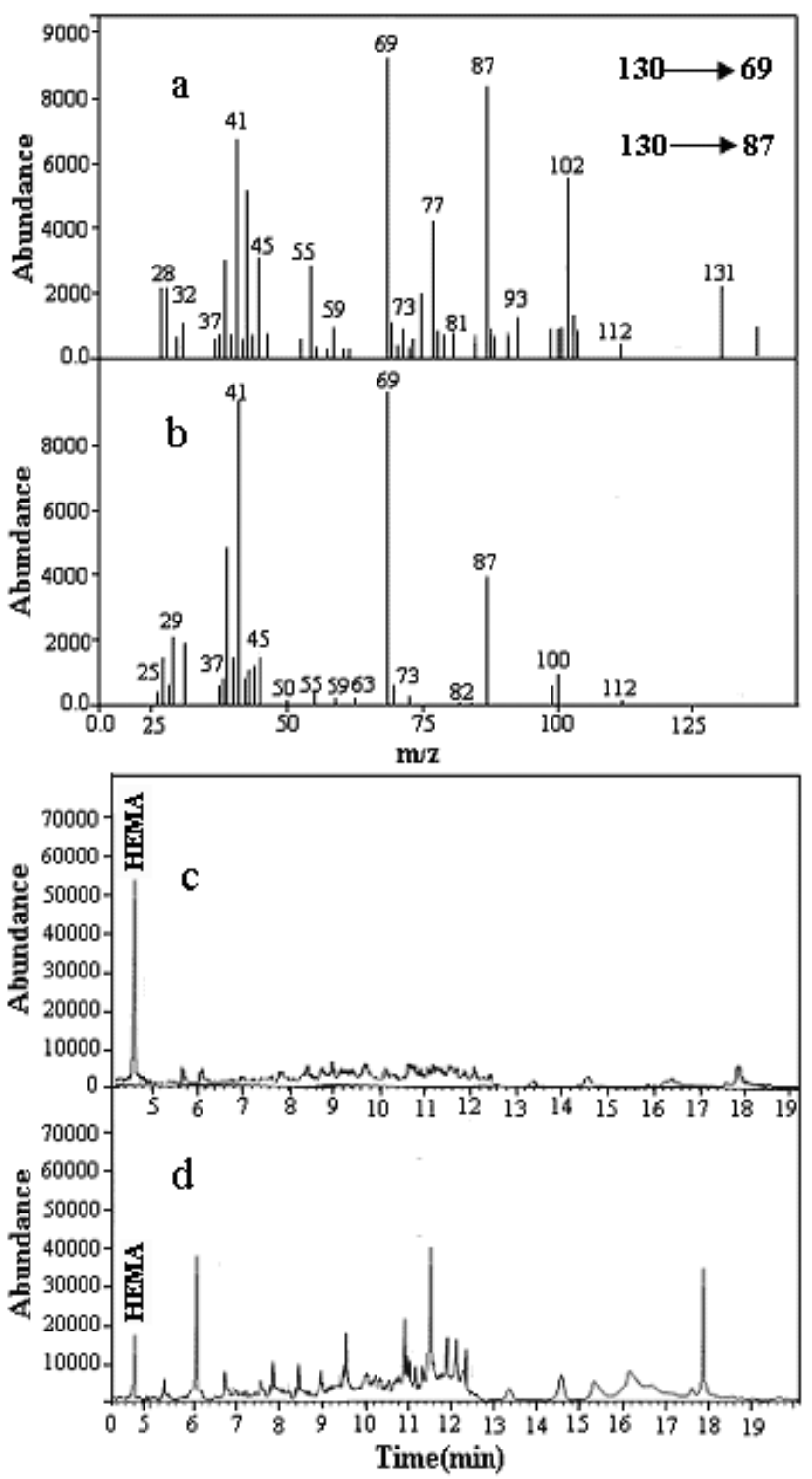

Figure 5 GCMS spectra of fragment ions of HEMA (a) Spectra of HEMA in SPH $\left(\mathrm{H}_{10}\right)$ (b) NIST library spectrum of HEMA.GCMS chromatograms of HEMA (c) HEMA standard $1.0 \mu \mathrm{g} / \mathrm{ml}$ (d) Residual HEMA in $\mathrm{SPH}\left(\mathrm{H}_{10}\right)$

\subsection{In vitro drug release study}

In vitro $\mathrm{DF}$ release from XG-g-poly [HEMAco-AA] SPH systems were evaluated in $\mathrm{pH}$ progressive media i.e. SGF as well as in SIF as the dissolution medium to see the release behavior in different $\mathrm{pH}$ conditions. The applied formulative variable i.e. change in monomer ratio in the crosslinked polymer was compared for their influence on drug release rate. By increasing the 
HEMA:AA monomer ratio to $1: 2$ in hydrogel, comparatively better release rate of DF was found in both the media. Formulation $\mathrm{H}_{6}$ showed slowest drug release profile in both the medium than other formulations and formulation $\mathrm{H}_{10}$ showed relatively more release in both the media (Fig. 7). The release of DF from the SPH system was found to be dependent on swelling properties of the SPH in particular medium. Comparatively much higher DF release was observed in SIF than that of SGF. This may be due to the higher swelling capacity of the system in SIF. DF release from SPH was found to be controlled up to $24 \mathrm{~h}$.

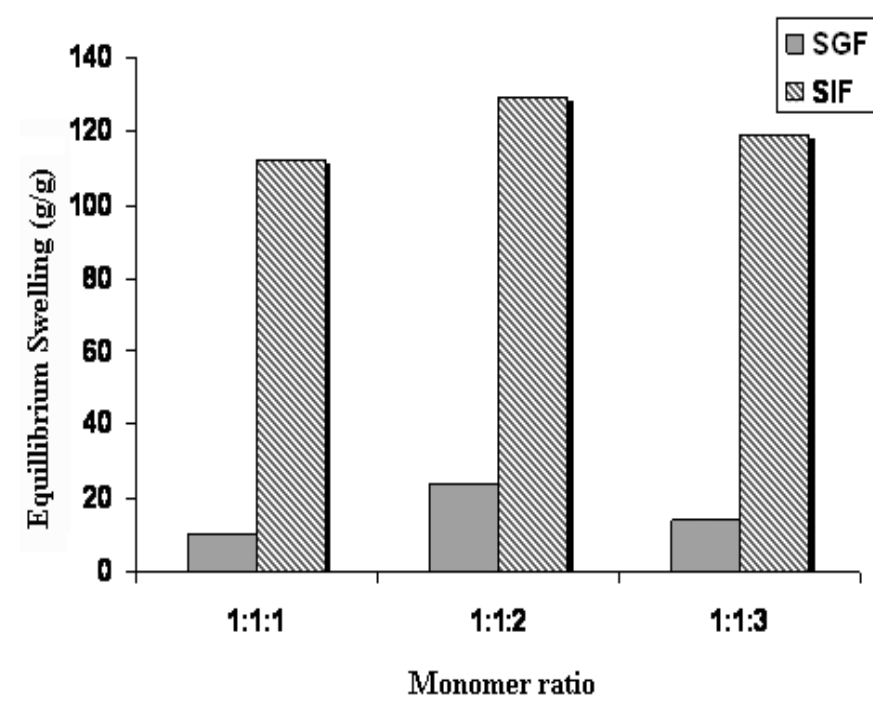

Figure 6 Equilibrium swelling $(\mathrm{g} / \mathrm{g})$ of $\mathrm{SPH}$ formulations $\mathrm{H}_{6}, \mathrm{H} 10$ and $\mathrm{H}_{11}$ with different XG: HEMA:AA ratio in biological media. SGF: Simulated Gastric fluid; SIF: Simulated Intestinal Fluid

Table 2 Doxofylline loading into XG-g-poly [HEMAco-AA], Xanthan gum: 1g, Lutrol $\mathrm{F}^{\circledR} 127$ : $100 \mathrm{mg}$, $\mathrm{NaHCO}_{3}: 0.5 \mathrm{~g}$

\begin{tabular}{|c|c|c|c|}
\hline $\begin{array}{c}\text { Polymer } \\
\text { Code }\end{array}$ & $\begin{array}{c}\text { HEMA:AA } \\
\text { (v/v ratio) }\end{array}$ & $\begin{array}{c}\text { \%DF } \\
\text { loading }\end{array}$ & $\begin{array}{c}\text { \%DF } \\
\text { entrapment }\end{array}$ \\
\hline $\mathrm{H}_{6}$ & $1: 1$ & $97 \pm 1.4$ & $69 \pm 1.9$ \\
\hline $\mathrm{H}_{10}$ & $1: 2$ & $98 \pm 2.3$ & $83 \pm 2.0$ \\
\hline $\mathrm{H}_{11}$ & $1: 3$ & $98 \pm 1.6$ & $74 \pm 1.4$ \\
\hline
\end{tabular}

\subsection{In vitro drug release kinetic mechanism}

To determine the mechanism of drug release from XG-g-poly [HEMA-co-AA] SPH matrices, different kinetic models like zero order kinetic, first order kinetic, Higuchi model were used. Regression coefficient $\left(\mathrm{R}^{2}\right)$ values of each kinetic models were compared to find out the best fit model. By comparing the $\mathrm{R}^{2}$ values of different models, Higuchi model was found to be best fit (Table 3). So it could be predicted that release of DF from the SPH formulations were of diffusion type. After storing the formulations for three months at accelerated stability condition i.e. $40^{\circ} \mathrm{C} / 75 \% \mathrm{RH}$ as per I.C.H. guidelines, the DF loaded SPH were found to retain the same drug content with minor deviations. Overall results from the stability studies indicated that formulations were physically and chemically stable for more than three months.

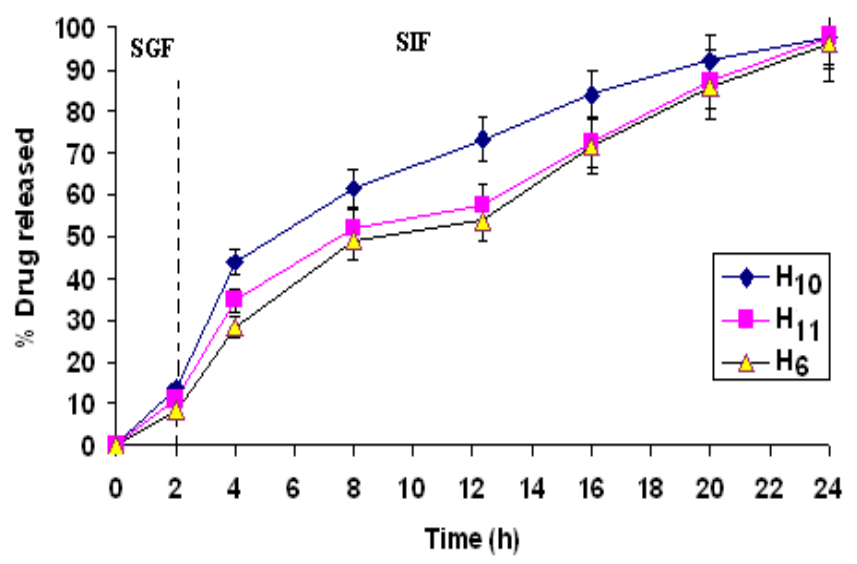

Figure 7 Comparison of \%DF release from DF loaded $\mathrm{SPH}$ formulations $\left(\mathrm{H}_{6}, \mathrm{H} 10\right.$ and $\left.\mathrm{H}_{11}\right)$ in $\mathrm{pH}$ progressive biological media.

\section{Conclusion}

XG-g-Poly (HEMA-co-AA) hydrogels were successfully synthesized in a straight forward way using conventional equipments. Characterization of SPH was done by FT-IR, TGA, SEM, HPLC and GCMS. The prepared SPH were successfully loaded with Doxofylline (DF) drug and formulation $\mathrm{H}_{10}$ showed higher \%drug content $(98 \pm 2.3)$ and \% drug entrapment efficiency (83 \pm 2.0$)$. Swelling studies of SPH were carried out in simulated media and swelling of SPH in SIF media was found to be much higher than that of SGF. The highest swelling capacity was obtained (c) 2010 by NWPII. All rights reserved. 
at 1:2 $(\mathrm{v} / \mathrm{v})$ ratio of HEMA: AA $\left(\mathrm{H}_{10}\right)$ in both the media. From the in Vitro drug release study in $\mathrm{pH}$ progressive media, formulation $\mathrm{H}_{10}$ showed comparatively higher release extending up to $24 \mathrm{~h}$.
From the drug release kinetic study, Higuchi model was found to be best fit among all the models. The mechanism of DF release from the SPH matrix was found to be of diffusion type.

Table 3. Fitting results of experimental DF release data of XG-g-poly [HEMA-co-AA] SPH formulations $\mathrm{H}_{6}-\mathrm{H}_{11}$ to different kinetic equations.

\begin{tabular}{|l|l|l|l|l|l|l|}
\hline Formulation & $\begin{array}{l}\text { Zero } \\
\text { order } \\
\left(\mathbf{k}_{\mathbf{0}}\right)\end{array}$ & $\mathbf{R}^{\mathbf{2}}$ & $\begin{array}{l}\text { First } \\
\text { order }\left(\mathbf{k}_{\mathbf{1}}\right)\end{array}$ & $\mathbf{R}^{\mathbf{2}}$ & $\begin{array}{l}\text { Higuchi } \\
\left(\mathbf{k}_{\mathbf{H}}\right)\end{array}$ & $\mathbf{R}^{\mathbf{2}}$ \\
\hline $\mathrm{H}_{6}$ & $\begin{array}{l}7.211 \\
(1.031)\end{array}$ & $\begin{array}{l}0.8665 \\
(0.010)\end{array}$ & $\begin{array}{l}0.416 \\
(0.039)\end{array}$ & $\begin{array}{l}0.9920 \\
(0.004)\end{array}$ & $\begin{array}{l}49.721 \\
(1.116)\end{array}$ & $\begin{array}{l}\mathbf{0 . 9 9 6 9} \\
(\mathbf{0 . 0 0 0 9})\end{array}$ \\
\hline $\mathrm{H}_{10}$ & 7.182 & 0.9011 & $\begin{array}{l}0.061 \\
(0.068)\end{array}$ & $\begin{array}{l}0.9938 \\
(0.0013)\end{array}$ & $\begin{array}{l}19.571 \\
(1.261)\end{array}$ & $\begin{array}{l}\mathbf{0 . 9 9 9 1} \\
(\mathbf{0 . 0 0 0 1})\end{array}$ \\
\hline $\mathrm{H}_{11}$ & $(1.046)$ & $(0.011)$ & 0.066 & $\begin{array}{l}0.9951 \\
(0.0004)\end{array}$ & $\begin{array}{l}21.061 \\
(1.174)\end{array}$ & $\begin{array}{l}\mathbf{0 . 9 9 7 9} \\
(\mathbf{0 . 0 0 1})\end{array}$ \\
\hline
\end{tabular}

Values in parenthesis mean S.D., $\mathrm{R}^{2}$ is the regression coefficient. Best results in bold

\section{Abbreviations}

XG, xanthan gum; SPH, superporous hydrogel; HEMA, 2-hydroxyethyl methacrylate; AA, acrylic acid; DF, doxofylline; APS, ammonium persulfate; $\mathrm{MBA}, \quad \mathrm{N}, \mathrm{N}^{\prime}$ _-methylene bis acrylamide; $\mathrm{NaHCO}_{3}$, sodium bicarbonate ; FTIR, Fourier transform infrared spectra; $\mathrm{KBr}$, potassium bromide; TGA, thermogravimetric analysis SEM, scanning electron microscopy; HPLC, high performance liquid chromatography; GCMS, gas chromatography mass spectrometry; MSD, mass selective detector; PDA, photodiode array; GIT, gastro intestinal; SGF, simulated gastric fluid; SIF, simulated intestinal fluid. PVDF, polyvinylidene fluoride.

\section{References}

1. Dai, P. H.; Minh, K. N.; Doo, S. L. Controlling the degradation of $\mathrm{pH} /$ temperature-sensitive injectable hydrogels based on poly $(\beta$-amino ester), Polym. Bull. 2010, 18, 192-197.

2. Narayan, B.; Jonathan, G.; Miqin, Z. Chitosanbased hydrogels for controlled localized drug delivery. Adv. Drug. Deliv. Re. 2010, 62, 8399.

3. Baljit, S.; Nirmala, C. Dietary fiber psyllium based hydrogels for use in insulin delivery. Int. J. Diabet. Melt. 2010, 2, 32-37.

4. Alireza, S.; Qiang, L.; Mohammad, J. A.; et al. Novel modified starch-xanthan gum hydrogels for controlled drug delivery: Synthesis and Characterization. Carbohydr. Polym. 2010, 79, 898-907.

5. Riadh, B. S.; Kacem, C.; Souhail, B.; et al. Optimisation of xanthan gum production by palm date (Phoenix dactylifera L.) juice byproducts using response surface methodology.

Food. Chem. 2010, 121, 627-633.

6. Clive, P. P. (2010) Doxofylline: A "Novofylline" Pulmon. Pharm. Therap. doi:10.1016/j.pupt.2010.04.002

7. Kinam, P.; Haesun, P. (1998) Superabsorbent hydrogel foams, US Patent 5750585

8. Jamshidi, A.; Ahmad Khan, B. F.; Kabiri, K et al. Optimized HPLC determination of residual monomer in hygienic SAP hydrogels. Polym. Test. 2005, 24, 825-828.

9. Xiaohua, Q.; Mingzhu, L.; Zhenbin, C.; et al. Study on the swelling kinetics of (C) 2010 by NWPII. All rights reserved. 382 
superabsorbent using open circuit potential measurement. Euro. Polym. J. 2008, 44,743754.

10. Carstensen, J.T.; C.T. Rhodes Drug stability, Principles and Practices; Marcel Dekker: New York, 2000.
11. Dos Santos, K. S. C. R.; Coelho, J. F. J.; Ferreira, P.; et al. Synthesis and characterization of membranes obtained by graft copolymerization of 2-hydroxyethyl methacrylate and acrylic acid onto chitosan. Int. J. Pharm 2006, 310, 37-45. 